\title{
Information Seeking Behavior About Cancer and Associated Factors Among University Students, Ethiopia: A Cross-Sectional Study
}

This article was published in the following Dove Press journal: Cancer Management and Research

\author{
Adugna Gedefaw' \\ Tesfahun Melese Yilma $\mathbb{D}^{2}$ \\ Berhanu Fikadie Endehabtu (iD) ${ }^{2}$ \\ 'Department of Health Informatics, \\ Debre Tabor Health Science College, \\ Gondar, Ethiopia; ${ }^{2}$ Department of Health \\ Informatics, Institute of Public Health, \\ College of Medicine and Health Sciences, \\ University of Gondar, Gondar, Ethiopia
}

Correspondence: Berhanu Fikadie Endehabtu

Department of Health Informatics, Institute of Public Health, College of

Medicine and Health Sciences, University

of Gondar, Gondar, Ethiopia

Tel +251921013129

Email berhanufikadie@gmail.com
Introduction: Cancer is among the leading cause of death in sub-Saharan Africa over the last few years, putting a tremendous physical, emotional, and financial strain on individuals, families, and health systems. Many health systems in sub-Saharan Africa are least prepared to manage this burden, and a large number of individuals do not have access to quality cancer-related information to prevent and manage cancer. Understanding the information seeking behavior of individuals, especially university students who are more likely to seek health information than other people, can be seen as an opportunity to provide resources to improve lifestyle or prevent possible health-threatening behaviors of individuals.

Objective: This study aimed to assess cancer information seeking behavior (CISB) and its associated factors among students in Debre Tabor University, Ethiopia.

Methods: An institution-based cross-sectional study design was conducted among students at Debre Tabor University from March 01 to March 30, 2019. A total of 844 students were selected using a multistage stratified sampling technique. Data were collected using a structured and pretested questionnaire by trained data collectors. Data entry and analyses were performed using Epi info version 7.2 and SPSS version 20, respectively. Descriptive and inferential statistics were used to explore the socio-demographic information and cancer information seeking behavior. Binary logistic regression was used to identify factors associated with cancer information seeking.

Results: The proportion of cancer information seeking by students in the past 12 months was $30.1 \%$. Their preferred source of information about cancer was health-care providers (48\%) followed by the Internet (27.6\%). Year of study, Internet access (AOR=6.07, 95\% CI= $4.05,9.10)$, health literacy level ( $\mathrm{AOR}=1.8,95 \% \mathrm{CI}=1.21,2.68)$, self-reported health condition $(\mathrm{AOR}=1.85,95 \% \mathrm{CI}=1.25,2.73)$, perceived susceptibility to cancer ( $\mathrm{AOR}=2.48,95 \%$ $\mathrm{CI}=1.47,4.2)$, and perceived severity of cancer $(\mathrm{AOR}=3.33,95 \% \mathrm{CI}=1.85,6.0)$ were the factors associated with cancer information seeking.

Conclusion: The proportion of cancer information seeking among university students was low. Being 3rd- and 4th-year student, internet access, being healthy, adequate health literacy level, concerning about cancer, and higher perceived severity of cancer were significantly associated with cancer information seeking. Increase health literacy and awareness creation about cancer for students will help to seek cancer information.

Keywords: cancer, information seeking behavior, university student, Ethiopia

\section{Introduction}

Cancer is a disease caused by an uncontrolled division of abnormal cells in the part of the body, and it is one of the most important causes of morbidity and mortality both in developed and developing world. ${ }^{1,2}$ The upswing of non-communicable 
diseases (NCD) has become an important issue for healthcare systems. In the past decades, national and international public health agencies across the globe have focused to control infectious and tropical diseases in developing countries.

According to the 2016 WHO projection, cancer burden will increase to 24 million new cases and 14.6 million cancer deaths will occur worldwide in 2035 . Of this, around $70 \%$ of cancer incidence will occur in developing countries. ${ }^{3}$ Ethiopia is among the developing countries which has a high burden of cancer morbidity and mortality. Findings from a research study conducted in 2018 showed that cancer incidence rate was 206 per 100,000 in Ethiopia. ${ }^{4}$

Efforts have been undertaken to minimize the burden of cancer in both developed and developing countries. Several African governments have developed and implemented operational national cancer control plans. ${ }^{5}$ More than 700 cancer registries were established worldwide. ${ }^{6}$ Ethiopia has also designed different cancer prevention strategies such as cancer comprehensive treatment and care, health promotion and disease prevention targeting on behavioral risk factors (avoid tobacco, alcohol, unhealthy diet and physical inactivity). ${ }^{7}$

However, the problem remains high. A way to minimize the burden of the disease could be through improving cancer information seeking behavior of individuals.

Effective communication on cancer-related information plays a significant role in the reduction of cancer burden since it has a substantial influence on lifestyle. ${ }^{8}$ Hence, there is a need to improve health information seeking behavior of individuals.

Health information seeking behavior (HISB) is the ways by which people obtain information about health, disease, health risk, and health promotion. ${ }^{9}$ Effective practice of health information seeking could bring health-enhancing actions and serves as an important means for understanding how an individual finds health information. ${ }^{10}$ Health information seeking practice is important in stress reduction and to increase awareness towards health risk factors. Currently, there is plenty of information related to cancer such as cancer prevention, cancer diagnosis, treatment and recovery. ${ }^{11}$ Information about cancer may have particular importance for cancer disease prevention. ${ }^{8,12}$ Understanding the cancer information seeking behavior of individuals, especially students who are more likely to seek health information than other people, can be seen as an opportunity to provide resources to improve lifestyle or prevent possible healththreatening behaviors among students. Therefore, this study aimed to determine the cancer information seeking behavior and its associated factors among university students.

\section{Methods and Materials Study Design and Setting}

An institution-based cross-sectional study design was conducted among students in Debre Tabor University from March 01-30/2019.

Debre Tabor University is one of the newly established public higher education institutions located $667 \mathrm{~km}$ far from Addis Ababa, the capital city of Ethiopia. The university has a clinic located centrally on the campus and it gives primary health-care services. The clinic has a laboratory, consultation, pharmacy, nursing services, medical records, wound dressing units and in-patient bed facilities for short-term admissions. The University has a total of 9572 students enrolled in 42 academic departments.

\section{Study Participants}

In this study, all undergraduate students in selected departments of Debre Tabor University were taken as the study population. All undergraduate students who were available during the data collection period were included while students with serious illness and unable to respond were excluded in this study.

\section{Sample Size Determination}

The sample size was calculated using single population proportion formula with the following assumptions: $95 \%$ confidence level $(\mathrm{CI}), \mathrm{Z}(1-\alpha / 2)=1.96)$, an expected proportion of cancer information seeking of $50 \%$, and $5 \%$ margin of error. As to investigators knowledge, in the country, there were no previously conducted studies which determined the proportion of cancer information seeking behavior in higher institution. Hence, $50 \%$ of the proportion of cancer was taken to estimate the required sample size. Furthermore, two sampling stage was applied to reach to the final study units in the process. Considering a design effect of two and a $10 \%$ non-response rate, the final sample size was 844 .

\section{Sampling Technique and Procedure}

A stratified multi-stage sampling method was employed to select study subjects. In the first stage, 42 (6 from health and 36 from non-health) departments were stratified based on health-related and non-health-related fields. Then, proportional allocations were made to select $13(30 \%)$ out of 
42 departments, 2 from health and 11 from non-healthrelated departments by using simple random sampling. Next, students were stratified by their years of study, assuming students' years of study and duration of stay in the campus would affect cancer information seeking behavior. The total number of students in the selected departments was distributed proportionally in each year of study. In the second stage, individual students from each stratum were selected using a simple random sampling technique.

\section{Study Variables}

In this study, cancer information seeking with an outcome of Yes or No was considered as the dependent variable while socio-demographic factors (age, gender, year of study, field of study, club participation, religion, ethnicity, prior residence, and internet access), behavioural factors (smoking, alcohol drinking, risky sexual behaviour, and physical activity), psychological factors (Perceived susceptibility to cancer, Perceived severity of cancer, Perceived health self-efficacy), and health-related factors (health status, cancer history, family cancer history, and health literacy level) were considered as independent variables.

\section{Measurements}

\section{Cancer Information Seeking}

Is the seeking of information about cancer from any source within the last one year before data collection started. ${ }^{13}$ Two item questions were used to measure cancer information seeking: 1)"Have you looked for information intentionally about cancer from any source?" and 2) "about how long ago was that?". 14

\section{Smoker}

Is a respondent who smokes currently either every day or sometimes.

\section{Alcohol Drinking}

To measure alcohol drinking, the AUDIT-C (Alcohol Use Disorder Identification Test) was used which quantifies alcohol misuse based on three Likert scale questions. It is a modified, shortened version of the 10-question AUDIT instrument developed by the WHO. AUDIT-C mean scores $\geq 4$ for male and $\geq 3$ for females are considered as alcohol drinker or alcohol miss-use. ${ }^{15}$

\section{Health Self-Efficacy}

Is measured using a single item question: "Overall, how confident are you about your ability to take good care of your health". The question is a measure of 5 scales $(1=$ not confident at all to $5=$ completely confident).

\section{Perceived Susceptibility to Cancer}

Is measured using a single item question: "How concerned are you about getting cancer disease?" The question is a measure of 5 scales ( $1=$ very unlikely to $5=$ very likely $)$.

\section{Perceived Severity}

Is measured using a single item question: "When I think about cancer, I automatically think about death". The question is a measure of 5 scales $(1=$ not at all to $5=$ extremely). ${ }^{5}$

\section{Health Literacy}

European health literacy survey questionnaire was used to measure health literacy level which has 47 items. The items are assessed using a 4-point scale (very easy=4, easy $=3$, difficult $=2$ and very difficult $=1$ ) and the score is divided into 4 categories: "inadequate", "problematic", "sufficient" and "excellent" health literacy. An index is computed by the formula, Index=mean-1*(50/3). If the index is in between 1 and 13.75 the health literacy is "Inadequate", in between 13.76 and 25.5 the health literacy is "Problematic", in between 25.6 and 37.5 the health literacy is "Sufficient" and $>37.5$ the health literacy is "Excellent". 16

\section{Data Collection Tool}

Self-administered, Amharic version questionnaire comprised of demographic, behavioural, psychological, and health-related factors was used. Health literacy questions are adopted from the European Health Literacy Survey. ${ }^{16}$ Cancer information seeking questions are mainly adapted from the Health Information National Trend survey 2014. ${ }^{17}$ The questionnaire was first developed in English and then translated to the Amharic language to make the data collection process simple and translated back to check the content validity of the original version. The questionnaire was pre-tested in the University of Gondar for suitability before the actual data collection started and feedbacks were communicated appropriately.

\section{Data Collection Procedures}

A total of five data collectors and two supervisors were recruited. Training was given for two days to data collectors and supervisors on the objective of the study and the questionnaire. Data were collected by well-trained data collectors using a pretested questionnaire. Close follow 
up and supervisions during the data collection period were carried out. Every questionnaire was reviewed and checked for completeness and consistency and appropriate corrections were made.

\section{Data Processing \& Analysis}

Data were entered into Epi-info version 7.2 and transferred to SPSS version 20.0 for statistical analysis. Data quality was checked for completeness and consistency by running frequencies, proportions, and summary statistics. Descriptive statistics were used to describe cancer information seeking and socio-demographic characteristics of the study participants. In addition, binary logistic regression analysis method was used to identify factors associated with cancer information seeking. Odds ratio with $95 \%$ confidence interval was considered to determine the strength of association between cancer information seeking and its predictors. All assumptions and model fitness were checked. A p-value of less than 0.05 was used as a cut of value for statistically significant findings.

\section{Ethical Consideration}

Ethical approval was obtained from the University of Gondar, Institute of public health ethical review committee. Written permission letter was secured from the Debre Tabor University. Written informed consent was obtained from each participant. Participants were informed that their participation was voluntary, and the information obtained from them was kept confidential through no identifier was used. Participants' name was omitted from the questionnaires for assurance of confidentiality and privacy. All interviews were made at a suitable and secured place. All questionnaires were stored at a secured place.

\section{Results}

A total of 844 students participated in this study with a100\% response rate. The mean age of the participants was $23.59 \pm 3.78 \mathrm{SD}$ years with ranges from 18 to 38 years. The majority, $80.5 \%$ (679/844) of the study participants did not participate in any voluntary health club. About 53.9\% (455/844) of students were previously resided in rural areas, and $90.3 \%$ (762/844) of study participants were from non-health department. Table 1 provides detailed information about the sociodemographic characteristics of the study participants.
Table I Sociodemographic Characteristics of Respondents at Debre Tabor University, Northern Ethiopia, 2019 ( $n=844)$

\begin{tabular}{|c|c|c|c|}
\hline Variables & Category & Frequency & Percent \\
\hline \multirow[t]{2}{*}{ Age (in years) } & $<23$ & 391 & 46.3 \\
\hline & $>23$ & 453 & 53.7 \\
\hline \multirow[t]{2}{*}{ Gender } & Male & 442 & 52.4 \\
\hline & Female & 402 & 47.6 \\
\hline \multirow[t]{2}{*}{ Prior residence } & Urban & 389 & 46.1 \\
\hline & Rural & 455 & 53.9 \\
\hline \multirow[t]{2}{*}{ Club participation } & Yes & 165 & 19.5 \\
\hline & No & 679 & 80.5 \\
\hline \multirow[t]{4}{*}{ Religion } & Orthodox & 570 & 67.5 \\
\hline & Muslim & $|5|$ & 17.9 \\
\hline & Protestant & 86 & 10.2 \\
\hline & Catholic & 37 & 4.3 \\
\hline \multirow[t]{2}{*}{ Field of study } & Health-related & 82 & 9.7 \\
\hline & Non-health-related & 762 & 90.3 \\
\hline \multirow[t]{4}{*}{ Year of study } & Ist year & 361 & 42.8 \\
\hline & 2nd year & 234 & 27.7 \\
\hline & 3rd Year & 194 & 23.0 \\
\hline & 4th Year & 55 & 6.5 \\
\hline \multirow[t]{3}{*}{ Marital status } & Single & 718 & 85.1 \\
\hline & Married & 120 & 14.2 \\
\hline & *Others & 6 & 0.7 \\
\hline
\end{tabular}

Note: *Others include widowed and divorce.

\section{Behavioral Factors}

About 11.1\% (94/844) of the study participants drunk alcohol and $3.4 \%(29 / 844)$ had a history of cigarette smoking. Among all the study participants, $0.9 \%$ (8/844) of them had a personal history of cancer and only six students $0.7 \%$ (6/844) had a family history of cancer. Detail information about the behavioral factors of the participants is provided in Table 2 .

\section{Psychological Factors and Health Literacy} Out of the total study participants, only $37.2 \%$ (314/844) of them had adequate health literacy level. The majority, $82.9 \%(700 / 844)$ perceived that cancer is a severe disease, and $21 \%(177 / 844)$ perceived that they were very concerned about cancer. The psychological factors and health literacy information of the participants are presented in Table 3.

Cancer information seeking

Among all the study participants, 30.1\% (254/844) (95\% CI: (26.9-33.3\%) had seek information about cancer at least once in the past 12 months. Among Health related, 
Table 2 Behavioral Factors of Students to Cancer Information Seeking in Debre Tabor University 2019

\begin{tabular}{|c|c|c|c|}
\hline & Categories & Frequency & $\begin{array}{l}\text { Percent } \\
\text { (\%) }\end{array}$ \\
\hline Alcohol drinking & $\begin{array}{l}\text { Yes } \\
\text { No }\end{array}$ & $\begin{array}{l}94 \\
750\end{array}$ & $\begin{array}{l}11.1 \\
88.9\end{array}$ \\
\hline Physical activity & $\begin{array}{l}\text { Active } \\
\text { Inactive }\end{array}$ & $\begin{array}{l}411 \\
433\end{array}$ & $\begin{array}{l}48.7 \\
51.3\end{array}$ \\
\hline Smoking & $\begin{array}{l}\text { Smoker } \\
\text { Non-smoker }\end{array}$ & $\begin{array}{l}29 \\
815\end{array}$ & $\begin{array}{l}3.4 \\
96.6\end{array}$ \\
\hline Risky sexual behavior & $\begin{array}{l}\text { Yes } \\
\text { No }\end{array}$ & $\begin{array}{l}17 \\
827\end{array}$ & $\begin{array}{l}2 \\
98\end{array}$ \\
\hline $\begin{array}{l}\text { General health } \\
\text { condition }\end{array}$ & $\begin{array}{l}\text { Feel healthy } \\
\text { Feel less } \\
\text { healthy }\end{array}$ & $\begin{array}{l}429 \\
415\end{array}$ & $\begin{array}{l}50.8 \\
49.2\end{array}$ \\
\hline Cancer history & $\begin{array}{l}\text { Yes } \\
\text { No }\end{array}$ & $\begin{array}{l}8 \\
836\end{array}$ & $\begin{array}{l}0.9 \\
99.1\end{array}$ \\
\hline Family cancer history & $\begin{array}{l}\text { Yes } \\
\text { No } \\
\text { Not sure }\end{array}$ & $\begin{array}{l}6 \\
606 \\
232\end{array}$ & $\begin{array}{l}0.7 \\
71.8 \\
27.5\end{array}$ \\
\hline
\end{tabular}

about $55 \%(45 / 82)$ of students seek information about cancer (Figure 1).

\section{Source of Cancer Information}

Out of 254 cancer information seekers, 48\% (122/254) of the participants prefered health workers as their primary source of cancer information while the Internet, $27.6 \%$ (70/254) is their second choice. Other sources of cancer information used by the participants were their family members, friends, and traditional media such as television and radio. Figure 2 shows the preferred sources of cancer information among study participants.

\section{Type of Cancer Information Sought}

From the total cancer information seekers, about 37\% (94/ 254) of the participants had looked information about cancer prevention strategies, $36.2 \%(92 / 254)$ about signs and symptoms of cancer, $19.3 \%(49 / 254)$ about cancer treatment, and $7.48 \%(19 / 254)$ about the diagnosis of cancer. Concerning the types of cancer, about $40 \%$ (165/ 432) of the participants had looked about breast cancer followed by cervical cancer $22 \%$ (93/432). Liver cancer and colon cancer were the least types of cancer information sought by the students (Figure 3).
Table 3 Psychological and Health Literacy Variable to Cancer Information-Seeking Behaviour Among Student in Debre Tabor University 2019

\begin{tabular}{|l|l|l|l|}
\hline & Categories & Frequency & $\begin{array}{l}\text { Percent } \\
\text { (\%) }\end{array}$ \\
\hline Health literacy & $\begin{array}{l}\text { Adequate } \\
\text { Limited }\end{array}$ & $\begin{array}{l}314 \\
530\end{array}$ & $\begin{array}{l}37.2 \\
62.8\end{array}$ \\
\hline Health self-efficacy & Confident & 437 & 51.8 \\
& Not & 407 & 48.2 \\
confident & & \\
\hline Perceived susceptibility & Very & 177 & 21.0 \\
to cancer & Concerned & 435 & 51.5 \\
& Concerned & 232 & 27.5 \\
\hline $\begin{array}{l}\text { Perceived severity of } \\
\text { cancer }\end{array}$ & Sever & 700 & 82.9 \\
\hline
\end{tabular}

\section{Frequency of Cancer Information Seeking} More than half of the participants, 53.5\% (136/254), sought cancer information occasionally while nearly onefourth of the participants $28.7 \%$ (73/254) sought at least once a month (Figure 4).

\section{Factors Associated with Cancer Information Seeking}

From the total independent variables, students' field of study, year of study, club participation, Internet access, physical activity, health status and health literacy, perceived severity to cancer, perceived susceptibility and self-efficacy were found to have a significant association with cancer information seeking in the bivariate logistic regression analysis and considered for multivariable analysis. Age, sex, and residence were not significant in the bivariate analysis and were not considered for multivariable analysis. In the multivariable analysis, year of study, Internet access, physical activity, health status, health literacy, perceived severity and perceived susceptibility were identified as the factors associated with cancer information-seeking in the multivariable logistic regression analysis.

The result of this study revealed that the odds of seeking information about cancer among participants whose year of study was third and fourth years were twice (AOR $=2.29,95 \%$ $\mathrm{CI}=1.43,3.69)$ and four times $(\mathrm{AOR}=3.92,95 \% \mathrm{CI}=1.82$, 8.45 ) higher when compared to first-year students. Similarly, 


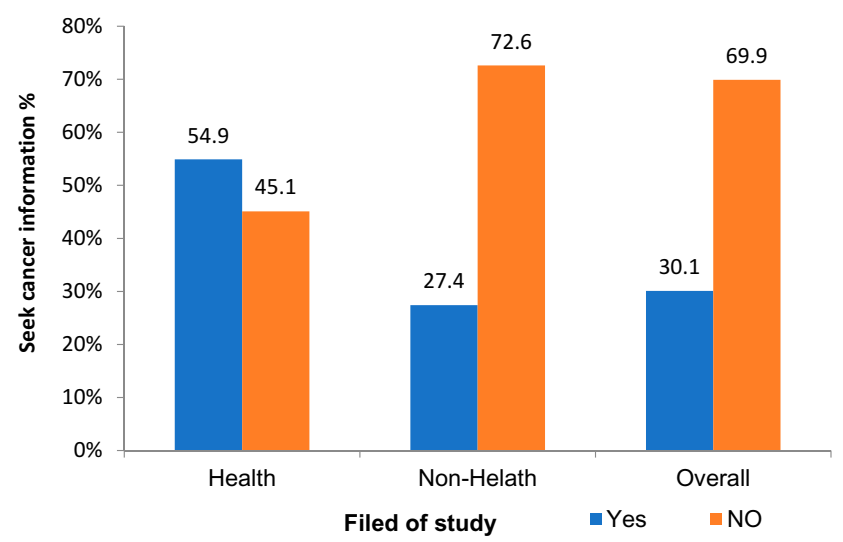

Figure I Cancer information seeking by students' field of study in Debre Tabor University, 2019.

the odds of seeking information about cancer among participants who were physically active was three times $(\mathrm{AOR}=3.05$, $95 \% \mathrm{CI}=2.10,4.43$ ) higher as compared to physically inactive participants. Regarding Internet access, the odds of seeking information about cancer among participants who had Internet access was six times $(\mathrm{AOR}=6.07,95 \% \mathrm{CI}=4.05,9.10)$ higher as compared to those who had no internet access.

Concerning health literacy, those participants with adequate health literacy level were two times $(\mathrm{AOR}=1.8,95 \%$ $\mathrm{CI}=1.21,2.68)$ more likely to seek information about cancer than those who had low health literacy level. Perceived health status was the other variable that turned out to have a significant association with cancer information seeking. That is, the odds of seeking information about cancer among participants who feel healthy was twice $(\mathrm{AOR}=1.85,95 \% \mathrm{CI}=1.25,2.73)$ higher when compared to those who feel less healthy.

Likewise, perceived susceptibility to and perceived severity of cancer had a significant association with cancer information seeking. The odds of seeking information about cancer among participants who were very concerned about getting cancer was 2.5 times $(\mathrm{AOR}=2.48,95 \%$ $\mathrm{CI}=1.47,4.20)$ higher when compared to those who were not concerned at all about getting cancer. Similarly, the odds of seeking information about cancer among participants who perceived cancer as severing was about three times $(\mathrm{AOR}=3.33,95 \% \mathrm{CI}=1.85,6.00)$ higher when compared to those who perceived cancer as not sever. Table 4 presents the results of the bivariate and multivariate analysis.

\section{Discussion}

In low-income settings, peoples are at risk of three burdens of health problems such as; communicable disease, traffic accidents and non-communicable diseases. With all these, cancer is among the public health importance and with low awareness by the community. University students are at risk for many health problems due to a lack of awareness and high exposure to risk factors. Also, cancer is a very devastating disease, the capacity of the country to screen, diagnose and treat cancer is very limited. This research study aimed to determine the proportion of cancer information seeking behaviour and to identify its associated factors.

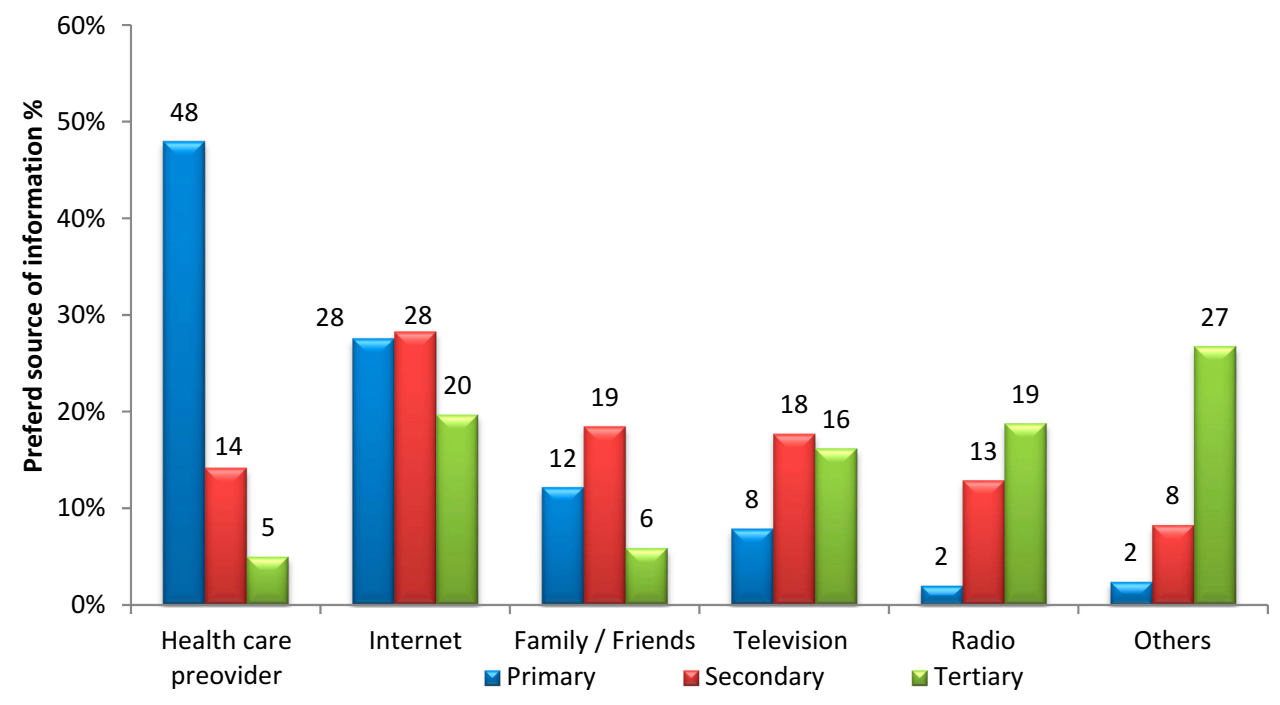

Figure 2 Preferred cancer information source of students in Debre Tabor University, 2019 ( $n=254)$. 


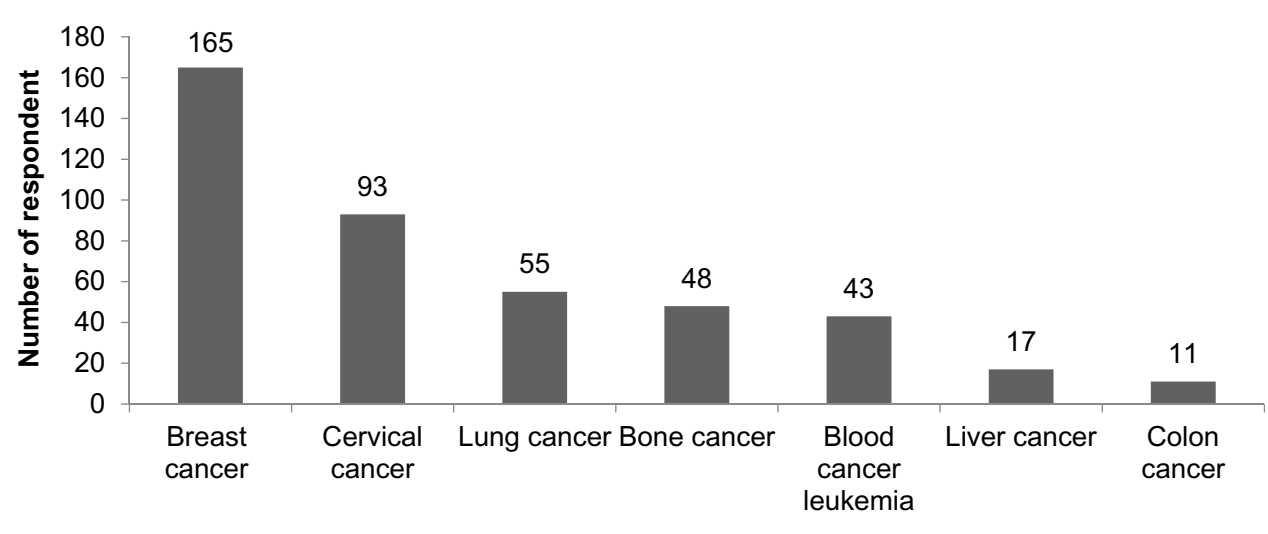

Types of cancer

Figure 3 Type of cancer-specific information sought by students in Debre Tabor University $(n=254)$.

Findings from this study revealed that only $30 \%$ of the students have sought cancer information. This finding is higher than a study conducted in Malaysia which showed the prevalence of information seeking about breast cancer was $22.5 \%{ }^{18}$ This difference could be because the former study included only breast cancer while the current study included seven types of cancer as presented in the result section. Similarly, the finding from the current study is higher than a study conducted in Hadiya zone, southern Ethiopia which showed the prevalence of information seeking about cervical cancer as $14.2 \% .{ }^{19}$ This difference could be due to the type of cancer information studied and the sociodemographic difference. The former study included community childbearing women while the current study included university students. University students are presumed to have adequate health literacy level which could increase their access to information about cancer. On the other hand, cancer information-seeking in this study was lower as compared to research studies conducted in the USA among cancer survivors which reported the prevalence of cancer information seeking as $53 \%,{ }^{13} 68 \%,{ }^{20}$ and $47.4 \%{ }^{21}$ The difference could be due to the high perceived severity of cancer among cancer survivors. Besides, the cancer survivors are likely to have an adequate level of health literacy and awareness about cancer information sources. Similarly, a study conducted in Malaysia among students on health information seeking was reported as $80 \%{ }^{22}$ which is higher than the current study. The difference could be the study in Malaysia was done on general health information seeking while the current study focused on cancer information seeking.

Regarding the source of cancer information, about $48 \%$ of cancer information seekers prefer health-care providers as their primary source of cancer information. This study is consistent with a study conducted in different regions of Ethiopia. ${ }^{23}$ The reason to chose health providers as the primary source of cancer information could be because they are the most trusted source of health information.

Regarding the factors associated with cancer information seeking, respondents' year of study was significantly

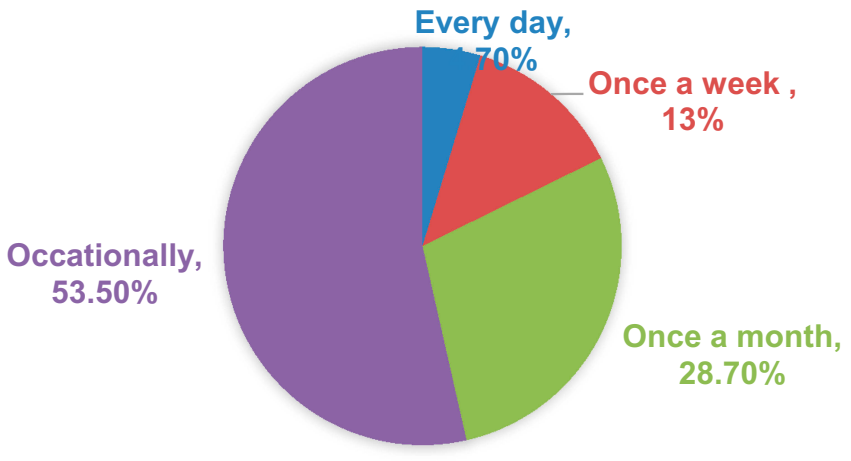

Figure 4 Frequency of cancer information seeking by students in Debre Tabor University $2019 n=(254)$. 
Table 4 Factors Associated with Cancer Information-Seeking Among Students in Debre Tabor University, Ethiopia, 2019 (n=844)

\begin{tabular}{|c|c|c|c|c|}
\hline \multirow[t]{2}{*}{ Variables } & \multicolumn{2}{|c|}{ Cancer Information Seeking } & \multirow[t]{2}{*}{ COR (95\%) } & \multirow[t]{2}{*}{ AOR (95\%) } \\
\hline & Yes (\%) & No (\%) & & \\
\hline \multicolumn{5}{|l|}{ Club participation } \\
\hline Yes & $69(42)$ & $96(58)$ & $1.92(1.35,2.73)$ & $1.49(0.96,2.30)$ \\
\hline No & $185(27)$ & $494(73)$ & I & I \\
\hline \multicolumn{5}{|l|}{ Field of study } \\
\hline Health-related & $45(55)$ & $37(45)$ & $3.22(2.03,5.11)$ & $1.42(0.78,2.56)$ \\
\hline Non-health-related & $209(27)$ & $553(73)$ & I & I \\
\hline \multicolumn{5}{|l|}{ Year of study } \\
\hline First year & $76(21)$ & $285(79)$ & I & I \\
\hline Second year & $75(32)$ & $159(68)$ & $1.77(1.22,2.57)$ & $1.32(0.84 .2 .05)$ \\
\hline Third year & $77(40)$ & $117(60)$ & $2.46(1.68,3.62)$ & $2.29(1.43,3.69)^{*}$ \\
\hline Fourth year & $26(47)$ & $29(53)$ & $3.36(1.87,6.04)$ & $3.92(1.82,8.45)^{*}$ \\
\hline \multicolumn{5}{|l|}{ Internet access } \\
\hline Yes & $210(44)$ & $262(56)$ & $5.975(4.16,8.59)$ & $6.07(4.05,9.10)^{* *}$ \\
\hline No & $44(12)$ & $328(88)$ & I & I \\
\hline \multicolumn{5}{|l|}{ Physical activity } \\
\hline Active & $180(44)$ & $23 \mid(56)$ & $3.78(2.75,5.20)$ & $3.05(2.10,4.43)^{* * *}$ \\
\hline Inactive & $74(17)$ & $359(83)$ & I & I \\
\hline \multicolumn{5}{|l|}{ Health literacy } \\
\hline Limited & $109(2 \mathrm{I})$ & 421 (79) & I & I \\
\hline Adequate & I 45 (46) & $169(54)$ & $3.31(2.44,4.50)$ & $1.80(1.21,2.68)^{*}$ \\
\hline \multicolumn{5}{|l|}{ Health status } \\
\hline Less healthier & $95(22)$ & $334(78)$ & I & I \\
\hline Feel healthier & $159(38)$ & $256(62)$ & $2.18(1.66,2.95)$ & $1.85(1.25,2.73)^{*}$ \\
\hline \multicolumn{5}{|l|}{ Perceived susceptibility } \\
\hline Not concerned & $55(24)$ & $177(76)$ & I & I \\
\hline Concerned & 116 (27) & $319(73)$ & $1.17(0.81,1.69)$ & $\mathrm{I} .52(0.96,2.4 \mathrm{I})$ \\
\hline Very concerned & $83(47)$ & $94(53)$ & $2.84(1.86,4.34)$ & $2.48(1.47,4.20)^{*}$ \\
\hline \multicolumn{5}{|l|}{ Perceived severity } \\
\hline Not sever & $20(14)$ & $124(86)$ & I & \\
\hline Sever & $234(33)$ & $466(67)$ & $3.11(1.89,5.12)$ & $3.33(1.85,6.00)^{* *}$ \\
\hline \multicolumn{5}{|l|}{ Health self-efficacy } \\
\hline Not confident & $86(2 I)$ & 321 (79) & I & \\
\hline Confident & $168(38)$ & $269(62)$ & $2.33(I .7|-3| 6)$ & $1.39(0.92,2.12)$ \\
\hline
\end{tabular}

Notes: $*$ Indicates $0.05<\mathrm{p}$-value $>0.001$, ** indicates $\mathrm{p}$-value $<0.00 \mathrm{I}, \mathrm{I}=$ reference category.

associated with cancer information seeking. Senior students were more seeker of information about cancer than juniors. This finding is in line with a study conducted in China/ Hong Kong. Participants with low educational attainment were less likely to seek health information. ${ }^{24}$ The probable explanation for this could be when the student's year of study increases their awareness towards the impact of cancer disease on human health increases and this leads to seeking information about cancer.
In this study, students' information seeking about cancer was associated with physical activities. Physically active students were three times more likely to seek information about cancer when compared to those students who were physically inactive. This study appeared to be consistent with a study done in Egypt. ${ }^{25}$ The possible explanation may be those students who are already involved in daily exercise have better understanding of promoting their health and they are concerned about their health 
status which in turn leads to seeking information about cancer.

In this study, perceived susceptibility to cancer and cancer information seeking was significantly associated. Students who are very concerned about getting cancer disease were two times more likely to seek information about cancer than students who are not concerned at all about getting cancer disease. This study is consistent with a study conducted in Belgium. ${ }^{26}$ Students who perceive susceptible to cancer are likely to seek health information to reduce their exposure to cancer.

Similarly, perceived severity of cancer also associated with cancer information seeking. Students who perceived cancer as sever were three times more likely to seek information about cancer when compared to those who did not perceive cancer as sever. This study is supported by a study conducted in the USA. ${ }^{21}$ Cancer severity can be described as deterministic thoughts about the external causes of the disease and the inevitability of death at diagnosis. $^{21}$ Individuals who perceive cancer as sever want to know the risk factors, prevention methods, diagnosis, and treatment of cancer. In addition, Internet access is associated with cancer information seeking. Cancer information seeking was six times higher among students who had Internet access when compared to those who had no internet access. This can due to that students with internet access can have access to search information easily. $^{27}$

Students' health literacy status also significantly associated with cancer information seeking. Students with adequate health literacy level were two times more likely to seek information about cancer than those who had limited health literacy level. This finding is consistent with a study conducted in the USA. ${ }^{21}$ The probable explanation for this association might be, whenever individuals' health literacy level increases they will be concerned about their health since cancer is the most devastating health problem. Accordingly, they will retrieve information about cancer due to the reason they fear to develop the health problem. ${ }^{21,28}$

Findings from this study revealed that healthier students more likely seek information about cancer than students who feel less healthy. This finding is consistent with a study conducted in Egypt. ${ }^{25}$ This might be that healthier people use information more frequently in proactive manner to maintain a healthy life style. ${ }^{25}$

Club participation, field of study and health selfefficacy was not significantly associated with health information seeking behavior about cancer.
Our study gives evidence on cancer information seeking behavior of university students. Some limitations should be noted. First, the study was a facility-based crosssectional study which may not tell as the causal inference. Self-reported data collection was used and there may have been a recall bias by the respondents.

\section{Conclusion}

Generally, the proportion of cancer information seeking among university students was low. The finding confirms health-care providers had been used as a primary source of information about cancer followed by the Internet. Most of the students retrieved information mainly to keep protecting themselves and their family or friends. In this study students were concerned to retrieve information regarding cancer was primarily about breast cancer even though there is different site-specific cancer disease. Most of the participants were concerned to retrieve information about the signs, symptoms and prevention methods of cancer. Year of study, Internet access, physical activity, health status, health literacy, perceived susceptibility, and perceived severity were factors significantly associated with cancer information seeking. Increasing health literacy status and availing internet access could improve the cancer information seeking behavior of students.

\section{Abbreviations}

CISB, cancer information seeking behavior; HISB, health information seeking behavior; NCD, non-communicable diseases; WHO, World Health Organization.

\section{Data Sharing Statement}

The datasets generated and/or analyzed during the current study will be available upon request from the corresponding author.

\section{Ethics Approval and Consent to Participate}

The study protocol was reviewed and approved by the ethical review board of the University of Gondar and written consent was obtained from each study participant. Permission letter also obtained from Debretabor Hospital. Names of patients and other personal identifiers were not included in the data collection tool.

\section{Acknowledgments}

The authors would like to thank the University of Gondar Institute of Public Health for the approval of ethical 
clearance. The authors also would like to thank the Debretabor University for the permission and data collectors, supervisors, and study participants for their participation in the study.

\section{Author Contributions}

All authors made substantial contributions to conception and design, acquisition of data, or analysis and interpretation of data; took part in drafting the article or revising it critically for important intellectual content; gave final approval of the version to be published; and agree to be accountable for all aspects of the work.

\section{Funding}

No funding.

\section{Disclosure}

The authors declare that they have no competing interests.

\section{References}

1. Boland CR, Thibodeau SN, Hamilton SR, et al. A National Cancer Institute Workshop on Microsatellite Instability for cancer detection and familial predisposition: Development of international criteria for the determination of microsatellite instability in colorectal cancer. AACR; 1998.

2. Zech DF, Grond S, Lynch J, Hertel D, Lehmann KA. Validation of World Health Organization guidelines for cancer pain relief: a 10-year prospective study. Pain. 1995;63(1):65-76.

3. Ferlay J, Soerjomataram I, Dikshit R, et al. Cancer incidence and mortality worldwide: sources, methods and major patterns in GLOBOCAN 2012. Int $J$ Cancer. 2015;136(5):E359-E86.

4. Timotewos G, Solomon A, Mathewos A, et al. First data from a population based cancer registry in Ethiopia. Cancer Epidemiol. 2018;53:93-98.

5. Stefan DC, Elzawawy AM, Khaled HM, et al. Developing cancer control plans in Africa: examples from five countries. Lancet Oncol. 2013;14(4):e189-e95.

6. Bray F, Soerjomataram I, Mery L, Ferlay J. Improving the quality and coverage of cancer registries globally. Lancet. 2015;386 (9998):1035-1036.

7. Non-Communicable O. National Strategic Action Plan (Nsap) for Prevention \& Control of Non-Communicable Diseases in Ethiopia.

8. Kelly B, Hornik R, Romantan A, et al. Cancer information scanning and seeking in the general population. J Health Commun. 2010;15 (7):734-753.

9. Lambert SD, Loiselle CG. Health information-seeking behavior. Qual Health Res. 2007;17(8):1006-1019.

10. Chaudhuri MS, Le MT, White MC, Thompson H, Demiris G. Examining health information-seeking behaviors of older adults. Comput Inform Nurs. 2013;31(11):547. doi:10.1097/01.NCN.000043 2131.92020 .42
11. Viswanath K. The communications revolution and cancer control. Nat Rev Cancer. 2005;5(10):828. doi:10.1038/nrc1718

12. Niederdeppe J, Frosch DL, Hornik RC. Cancer news coverage and information seeking. $J$ Health Commun. 2008;13(2):181-199. doi:10.1080/10810730701854110

13. Shim M, Kelly B, Hornik R. Cancer information scanning and seeking behavior is associated with knowledge, lifestyle choices, and screening. J Health Commun. 2006;11(sup001):157-172. doi:10.108 0/10810730600637475

14. Services USDoHaH. National Institutes of Health U.S. Department of Health and Human services; 2014.

15. Bush K. The AUDIT alcohol consumption questions (AUDIT-C) an effective brief screening test for problem drinking. Arch Intern Med. 1998;158(16):1789-1795. doi:10.1001/archinte.158.16.1789

16. Sørensen K, Van den Broucke S, Pelikan JM, et al. Measuring health literacy in populations: illuminating the design and development process of the European health literacy survey questionnaire (HLS-EU-Q). BMC Public Health. 2013;13(1):948.

17. Finney Rutten LJ, Davis T, Beckjord EB, Blake K, Moser RP, Hesse BW. Picking up the pace: changes in method and frame for the health information national trends survey (2011-2014). J Health Commun. 2012;17(8):979-989.

18. Muhamad M, Afshari M, Mohamed NA. Internet use and breast cancer survivors. Turkish Online J Educ Technol TOJET. 2011;10 (4):241-247.

19. Habtu Y, Yohannes S, Laelago T. Health seeking behavior and its determinants for cervical cancer among women of childbearing age in Hossana Town, Hadiya zone, Southern Ethiopia: community based cross sectional study. BMC Cancer. 2018;18(1):298.

20. Claridy MD, Hudson MM, Caplan L, et al. Patterns of internet-based health information seeking in adult survivors of childhood cancer. Pediatr Blood Cancer. 2018;65(5):e26954.

21. Kobayashi LC, Smith SG. Cancer fatalism, literacy, and cancer information seeking in the American public. Health Educ Behav. 2016;43(4):461-470.

22. Yilma TM, Inthiran A, Reidpath D, Orimaye SO. Health information seeking and its associated factors among university students: a case in a middle-income setting. Health. 2017.

23. Shiferaw N, Brooks MI, Salvador-Davila G, et al. Knowledge and awareness of cervical cancer among HIV-infected women in ethiopia. Obstet Gynecol Int. 2016;2016.

24. Wang MP, Viswanath K, Lam TH, Wang X, Chan SS. Social determinants of health information seeking among Chinese adults in Hong Kong. PLoS One. 2013;8(8):e73049.

25. Ghweeba M, Lindenmeyer A, Shishi S, Abbas M, Waheed A, Amer S. What predicts online health information-seeking behavior among Egyptian adults? A cross-sectional study. J Med Internet Res. 2017;19(6):e216.

26. Nelissen S, Beullens K, Lemal M, Van den Bulck J. Fear of cancer is associated with cancer information seeking, scanning and avoiding: a cross-sectional study among cancer diagnosed and non-diagnosed individuals. Health Info Libr J. 2015;32(2):107-119.

27. Ibegbulam IJ, Akpom CC, Enem FN, Onyam DI. Use of the Internet as a source for reproductive health information seeking among adolescent girls in secondary schools in Enugu, Nigeria. Health Info Libr J. 2018;35(4):298-308.

28. Sparks L, Nussbaum JF. Health literacy and cancer communication with older adults. Patient Educ Couns. 2008;71(3):345-350. 


\section{Publish your work in this journal}

Cancer Management and Research is an international, peer-reviewed open access journal focusing on cancer research and the optimal use of preventative and integrated treatment interventions to achieve improved outcomes, enhanced survival and quality of life for the cancer patient.
The manuscript management system is completely online and includes a very quick and fair peer-review system, which is all easy to use. Visit http://www.dovepress.com/testimonials.php to read real quotes from published authors. 